\title{
EL PALACIO DE CHAPULTEPEC EN 1700 \\ $\mathbf{P} \mathbf{O}$
}

MANUEL ROMERO DE TERREROS

Durante muchos años se conservó en la Hacienda de Bojay, en el hoy Estado de Hidalgo, un biombo pintado al óleo sobre tela, coronada cada una de sus diez hojas con una cresteria de madera calada, dorada y policromada. Imitaba por un lado una mampara de laca de Coromandel, con tal maestria ejecutada, que solamente de cerca y al tacto se comprobaba que no estaba hecha de madera laqueada sino de pintura sobre lienzo. En el centro de una multitud de característicos motivos decorativos chinos, se destacaba un gran medallón, poblado a su vez de figuras europeas de la época de Luis XIV, pero interpretadas con criterio oriental.

Sin embargo, que el biombo fué confeccionado en la Nueva España. lo comprueba plenamente su anverso, en el cual se representó una escena netamente mexicana. Es por lo tanto evidente que el anónimo pintor tuvo a la vista un legítimo biombo chino que copió por un lado, mientras que el otro lo ejecutó a mano libre.

Para salvar el biombo de su ulterior ruina, el Duque de Castro Terreño, dueño de la Hacienda de Bojay, lo llevó consigo a Paris hace algunos años, y mientras conservó como biombo propiamente dicho la cara que 
imitaba la laca de Coromandel, hizo restaurar la parte opuesta en forma de cuadro; pero debido a su tamaño, tuvo que dividirse la pintura en tres secciones, con cuatro hojas para la central y tres para cada una de las laterales. Eil conjunto resultó una animadísima representación pictórica de los festejos que se celebraron en Chapultepec en el año de 1702, con ocasión de la llegada a México del trigésimo cuarto Virrey de la Nueva España, don Francisco Fernández de la Cueva, Duque de Alburquerque.

Efectivamente, en cuanto el antecesor de este gobernante, don Juan de Ortega Montañés, Arzobispo de México, tuvo aviso de la próxima llegada de Alburquerque, decidió efectuar la transmisión de poderes con mayor solemnidad y fausto que de costumbre. $\mathrm{E}$ día 18 de noviembre salió a recibirio a Otumba, según Alamán, "con muchas carrozas soberbias y los criados vestidos con costosas libreas, llevando en una de ellas su secretario, con mucha ceremonia, el bastón que iba a entregarle". 1 Cuatro días después llegó la comitiva a Guadalupe, en donde "tenía prevenido el mismo Arzobispo Montañés un espléndido convite", y después de acompañar al nuevo Virrey a comer, "lo condujo en la tarde a Chapultepec. En la casa o palacio que en aquel lugar había, estaba prevenido el alojamiento. y era la diversión de la ciudad en los días anteriores a la llegada del Virrey, ir a ver esos preparativos". La casa, dice Robles, "estaba ricamente colgada y adornada, y entre otras preseas ricas había dos escritorios embutidos de plata muy curiosos, tan altos que llegaban a las vigas y tenían dos varas de ancho, y estaban apreciados en quince mil pesos. Estaba cercada la plaza para los toros; habia en ella muchos puestos de frutas y cosas comestibles $y$ cocineras, los tablados pintados, aguas $y$ dulces $y$ gran concurso". 2

En Chapultepec recibió Alburquerque a todas las autoridades que fueron a presentársele, $y$ alli se le obsequió con todo género de diversiones, entre otras, una corrida de toros que se celebró el 28 del mes citado.

Estos festejos fueron, pues, el asunto del cuadro que se quiso representar en el anverso del biombo, cuyas diez hojas primitivas quedaton convertidas, como se ha dicho, en tres bastidores, que con todo cuidado conserva en su poder el señor don Ignacio de Villar Villamil.

En el bastidor central se destaca prominentemente el palacio que, al parecer, estaba emplazado en el sitio que hoy ocupa el Museo de Caza y Pesca.

1 Lncas Alamán. Disertaciones historicas. México, 1845.

2 Antonio de Robles, Diario de sucesos notables, Mérico. 1853. 
Es de tres pisos y del estilo arquitectónico de tiempos de Felipe IV y Carlos II. Coronan los ángulos de su fachada dos estatuas $y$, en esta ocasión, adornan sus alturas flámulas y gallardetes de vivos colores. Un cuerpo lateral, saliente, con vista al Sur, también es de tres pisos, mientras que el opuesto, al Norte, solamente tiene dos, con una galería en el superior, desde la cual se admira un jardín formal, encuadrado por alta y esbelta arqueria, $y$ en medio de cuyos prados y fuentes damas y caballeros discurren plácidamente. Detrás del palacio asoma un florido huerto.

En la explanada de enfrente, se elevan dos templetes de gusto barroco que cobijan sendas fuentes, y en el espacio intermedio se efectúa la corrida de toros a que se ha aludido. "Vénse en este espectáculo de lidia, dice un autor, cuatro caballeros, con las Cruces de Alcántara, Santiago y Calatrava, con trajes de la época de Felipe IV, y jinetes en briosos corceles que ostentan vistosas cubiertas de ricas telas y costosos jaeces. Uno de los caballeros ejecuta magistralmente la suerte de rejonear al toro, viniendo al quite uno de sus pajes, pues cada caballero está acompañado de dos. Los jinetes que están detrás de la fiera, empuñan sendas lanzas, de las usadas entonces para alancear toros bravos. Aparte del peón de brega, pueden verse los otros pajes con capas de lidia, rojas." I

Tan movida y pintoresca faena es observada, y seguramente aplaudida, por un selecto concurso de damas y caballeros desde los balcones y ventanas de Palacio. El balcón sobre la puerta principal, custodiada ésta por dos Granaderos de la Guardia, se adorna con un rico repostero de damasco rojo con las Armas Reales bordadas en oro y plata, y sirve de palco al nuevo Virrey, empelucado y cubierto con tricornio, a quien acompaña la Virreina y su dama. A, la izquierda de este balcón, se ve el que ocupa el Arzobispo Ortega Montañés, con otro Prelado y dos eclesiásticos más, mientras que el del lado derecho alberga a numerosas damas de la nobleza colonial. Las ventanas del piso bajo sirven de marco, como a otros tantos retratos, a señorones y damas, una de éstas con un niño en brazos y otra sentada en el suelo. En los demás balcones del edificio, así como en la galería del ala Norte, asoman los Oficiales Reales y otros miembros de la corte virreinal, principalmente señoras, de una de las cuales, con mantilla blanca en el tocado y en la mano un abanico, implora un mendigo una limosna, sin temor de que se lo impida un oficial que ve salir de la puerta del costado Sur del Palacio, una patrulla de otros Grana-

1 Nieolás Rangel. Historia del roreo en México. Mdxico, 1924. 
deros. Dos negros vestidos a la francesa y dos indios amenizan la jornada tocando aquéllos sus oboes y éstos sus timbales; y no faltan, para dar mayor nota de mexicanidad al cuadro, tres indígenas con la escasa indumentaria y los penachos de plumas multicolores que se supone usaban los antiguos guerreros aztecas, armados los tres de flechas, carcajes y macanas, y el primero portando; además, un florido estandarte. Albarderos, aquí y allá, guardan el orden.

En el primer bastidor, o sea el de la izquierda, se destaca, sobre frondosa arboleda, el acueducto que conduce el agua de Santa Fe, con arcos más elevados de lo que fueron en realidad; $y$ al fondo se perfila la serranía occidental del Valle, y se columbra a lo lejos el Santuario de los Remedios. Ocupa el centro de este cuadro un forlón tirado por un tronco de mulas, en el que liegan dos damas con una esclava negra en el estribo. Más allá, en las dependencias de servicio de Palacio, se distinguen un caballo y una vaca con su becerro, asi como esclavos y sirvientes, una de las cuales lleva a cabo la prosaica tarea de lavar ropa en un arroyo que por allí corre. En primer término, anima la escena una mascarada en la que Polichinela, Arlequín y otros personajes de la Comedia Italiana ejecutan alegre danza, en la que va a tomar parte también otra figura que sale, ya vestida, de la caseta que se ve detrás de la carroza. Varias personas contemplan el festejo, mientras que otras; a una mesa cercana, comen y beben más de lo debido.

Otra mascarada por el estilo se rẹpite en el primer término del tercer bastidor, o sección, del cuadro. Enanos y figuras ridiculas bailan alegremente al son de una guitarra que toca un viejo cubierto con enorme sombrero, $y$ en presencia de dos damas, un caballero, una dueña, una india vistosamente ataviada $\mathrm{y}$ dos chiquillos de largas trenzas, amplias faldas y mangas esponjadas de encaje. Por cierto que, a espaldas de las niñas, un indio está dispuesto a dispararles una flecha.

Ninguno de ellos parece darse cuenta de la enorme y dorada carroza que llega, con la Virreina sentada a la testera y dos de sus damas enfrente, - "al vidrio", como se decía entonces. $Y$ no debe extrafiarse que aquí se repita la figura de la Duquesa de Alburquerque, que ya se ha visto junto con su marido en el balcón principal de Palacio, porque hay que tener presente que el autor del cuadro no pretendió pintar todos los fes- 
tejos como simultáneos, sino más bien como una sucesión de ellos, a diversas horas de un mismo día, o de varios. La carroza viene tirada por seis caballos, que manejan dos postillones, y acompañada por los caballerospajes de rigor $y$, al estribo, el caballerizo mayor, montado en brioso $y$ enjaezado corcel.

A la derecha, en el ángulo inferior del cuadro, se distingue una choza, coronada con una parra con racimos de uvas y todo, en donde seguramente se expenden "las cosas comestibles y cocineras, las aguas y los dulces", de que nos habla Robles. Más allá, hay otras construcciones y una tupida arboleda; y por un lago o canal, que cruza elevado puente, bogan en canoas impelidas por remeros indios, otros concurrentes a las fiestas, que cantan y se acompañan con guitarras, mientras que, a un lado, dos graves Doctores de la Real y Pontificia Universidad conversan seriamente.

Como nota realista, se ven en áltimo término de esta sección del cuadro tres puestos de aguas frescas, antojos y, seguramente, pulque, cuyo abuso ha sido causa de que dos individuos de la clase infima entablen furiosa riña.

En contraste con escena tan prosaica, en todo el cuadro se ven volar enormes aves de maravilloso plumaje, que esmaltan el cielo con sus brillantes colores, y, a lo lejos, parvadas de pájaros más pequeños.

El vivo colorido de toda la pintura, las movidas escenas y las pintorescas figuras que la animan, compensan los defectos de dibujo, perspectiva y escorzo de que adolece; y tanto en conjunto como en detalle, constituye, a no dudarlo, un valioso documento para la historia de las artes suntuarias del Virreinato de la Nueva Espafia. 
DOI: http://dx.doi.org/10.22201/iie.18703062e.1945.13.398

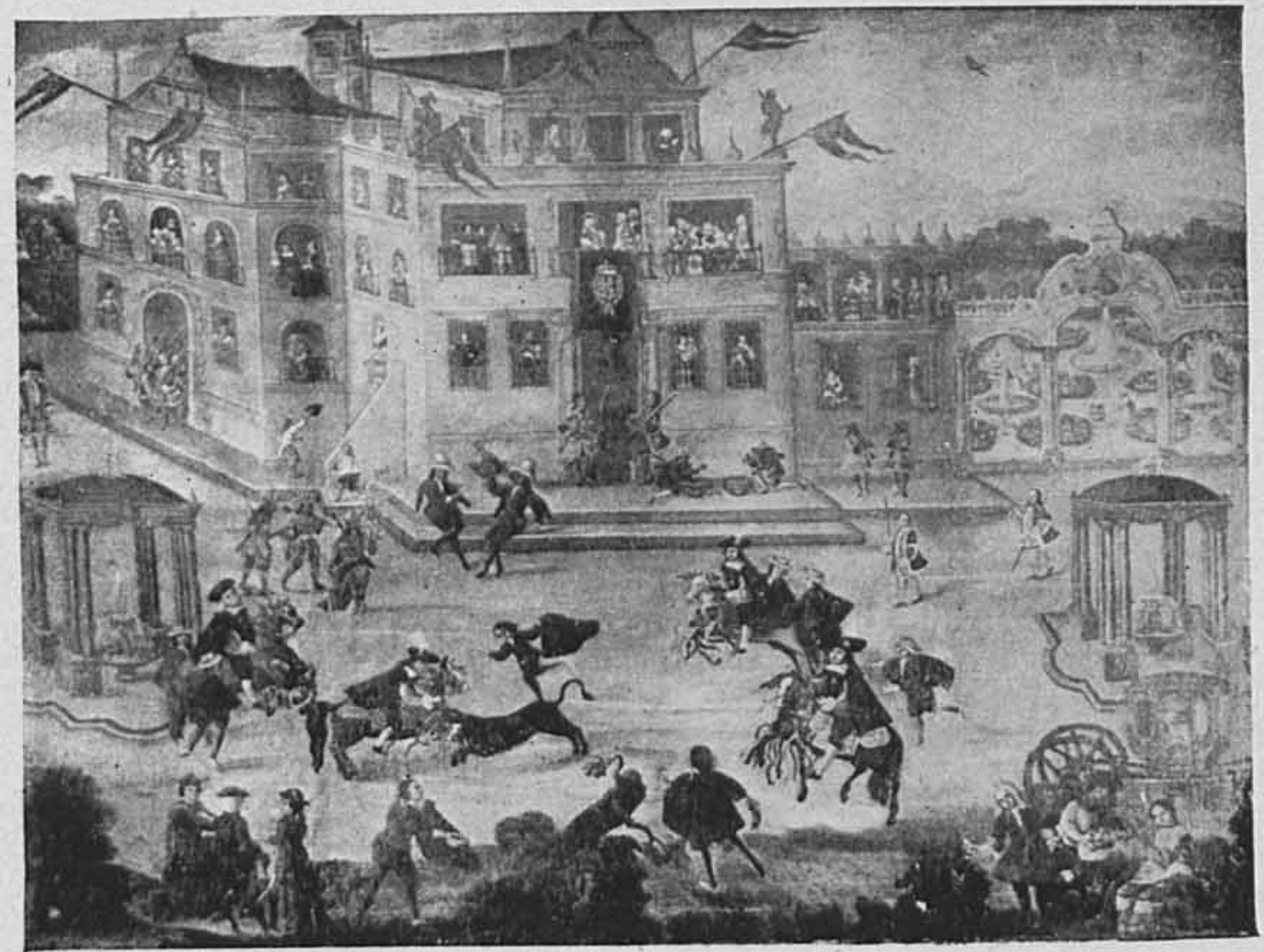

1. Bastidor central. El Palacio de Chapultepec 
DOI: http://dx.doi.org/10.22201/iie.18703062e.1945.13.398

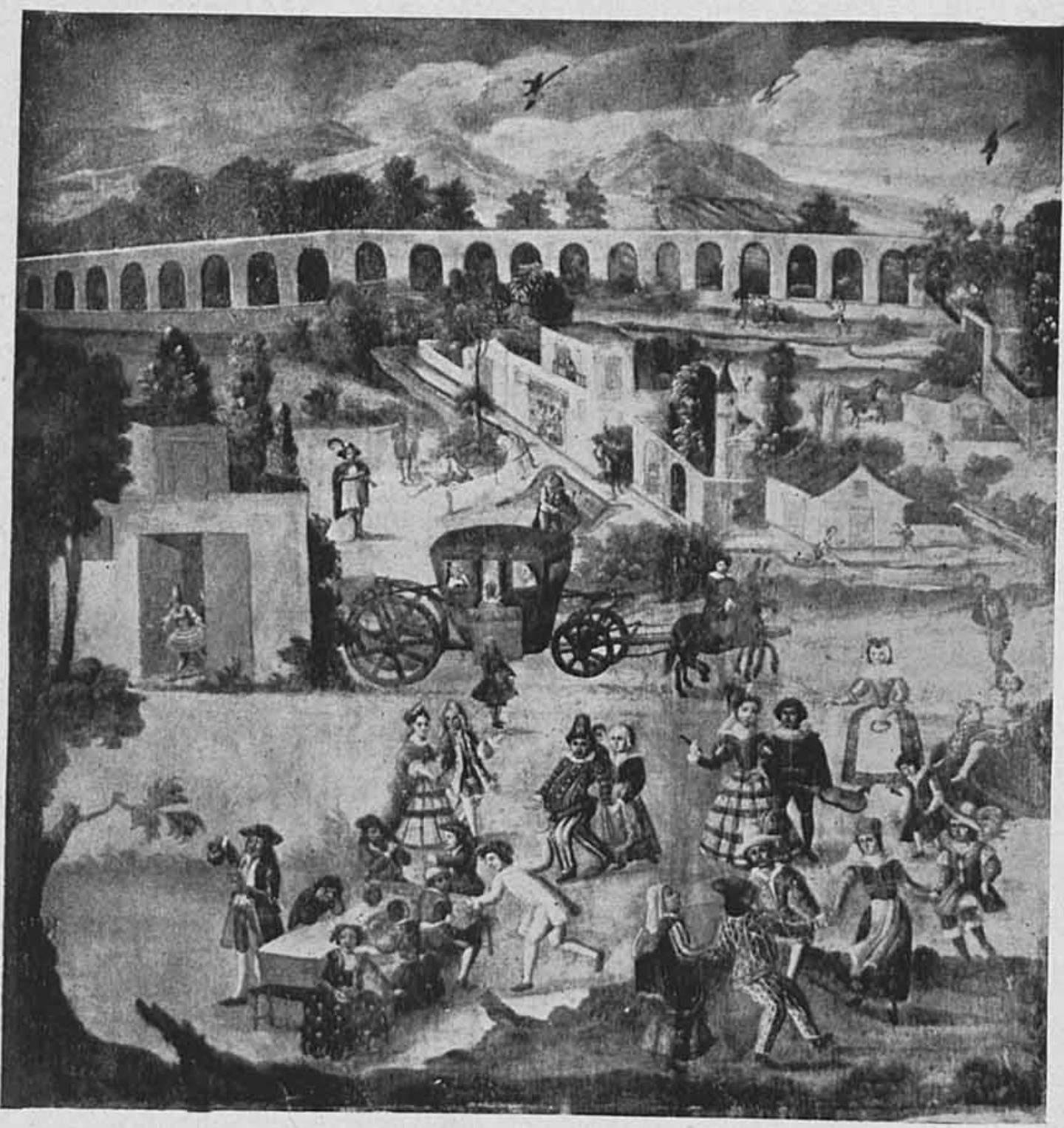

2. Bastidor de la izquierda. Mascarada y otros festejos 
DOI: http://dx.doi.org/10.22201/iie.18703062e.1945.13.398

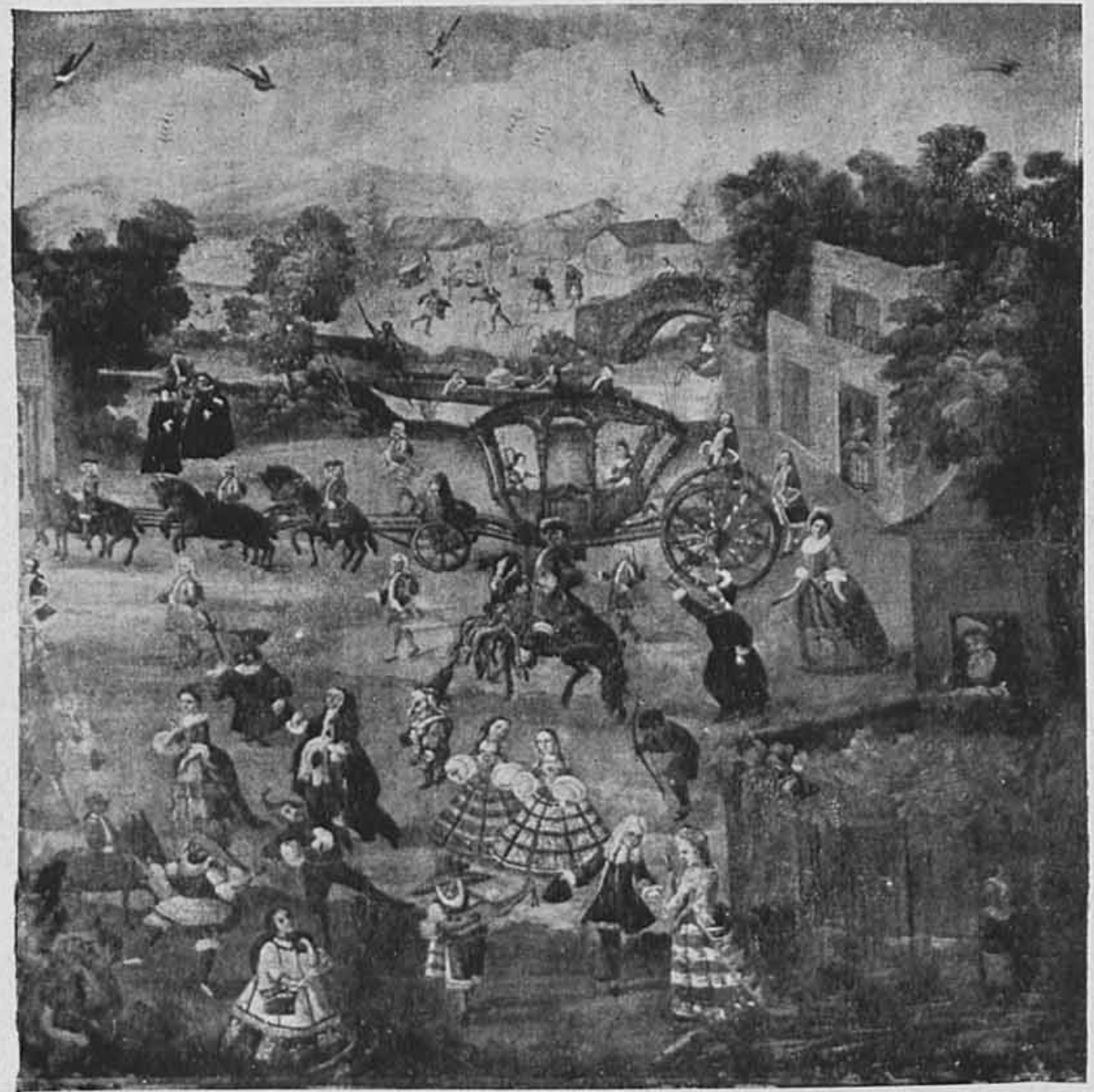

3. Bastidor de la derecha, Carroza de la virreina 
DOI: http://dx.doi.org/10.22201/iie.18703062e.1945.13.398

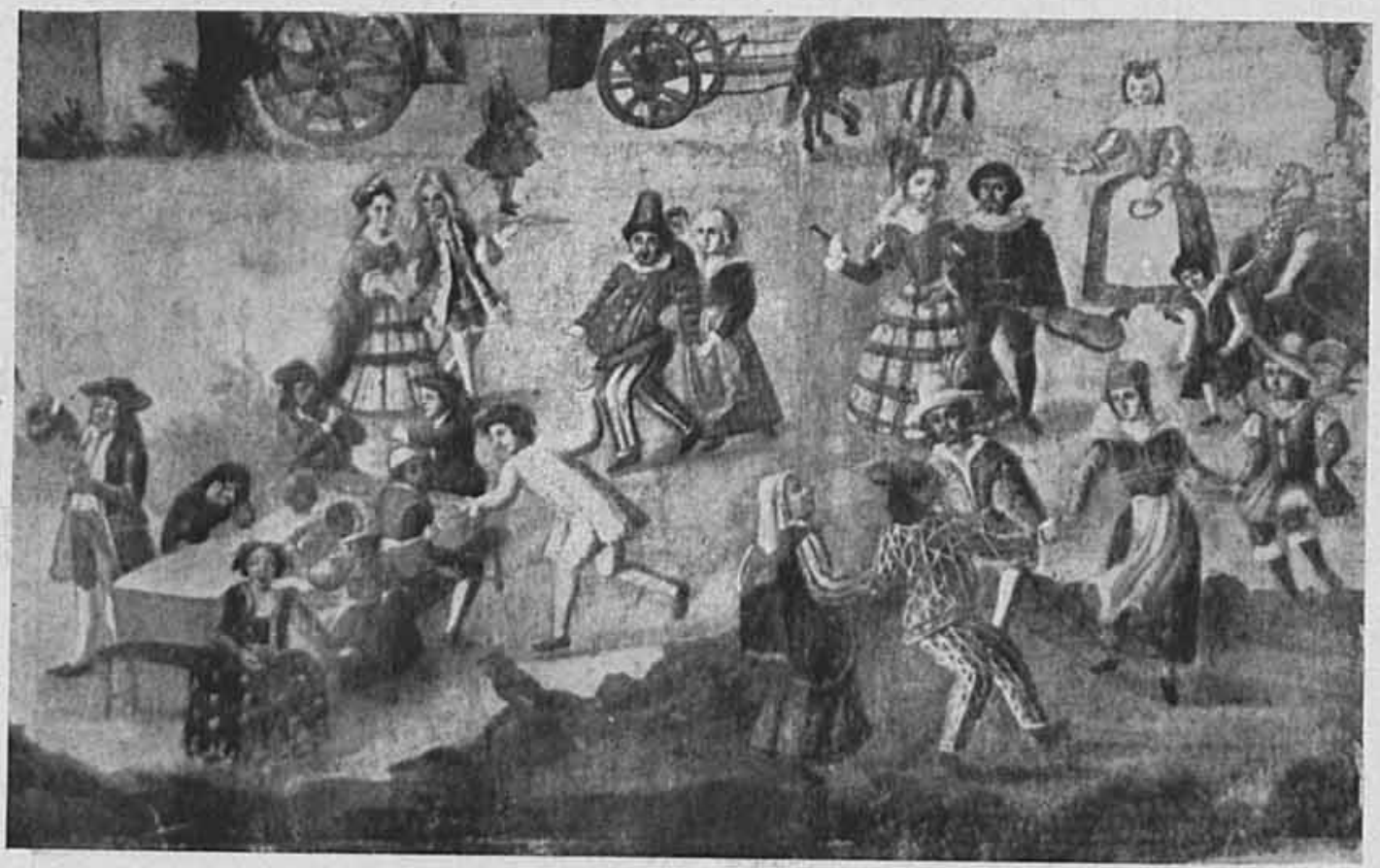

4. Detalle de la mascarada 